\title{
Artigos
}

Pamela Cristina dos Santos ${ }^{1}$

Patrícia de Moraes Lima² Gisely Pereira Botega ${ }^{3}$

\section{Risco e vulnerabilidade: desafios na rede de proteção à infância no município de Florianópolis}

\begin{abstract}
Resumo: Este artigo apresenta como a rede de proteção à infância está organizada no município de Florianópolis/SC a partir da política de assistência social situando o Serviço de Proteção e Atendimento a Famílias e Indivíduos (PAEFI) vinculado ao Centro Especializado de Assistência Social (CREAS/ILHA). A aproximação com o serviço CREAS/PAEFI/ILHA ocorre através do projeto de extensão desenvolvido pelo Núcleo Vida e Cuidado: estudos e pesquisas sobre violências (CED/UFSC), intitulado como "Rede de proteção, defesa e controle dos direitos: mapeamento do risco e da vulnerabilidade na infância em Florianópolis". Neste artigo buscamos problematizar as noções de risco e vulnerabilidade na infância trazendo alguns impasses e desafios da rede de proteção na atualidade. Observamos que no município datam da década de 1990 uma organização de políticas públicas da assistência social voltadas à proteção das crianças. Neste percurso vem se constituindo uma noção de rede intersetorial na qual saúde, educação e justiça, juntamente com os conselhos tutelares, tramam e atualizam noções de risco e vulnerabilidade.
\end{abstract}

Palavras-chave: Infância; Risco; Vulnerabilidade, Rede De Proteção; Política De Assistência Social.

\section{Risk and vulnerability: challenges in child protection network in Florianópolis}

Abstract: This article shows how the child protection network is organized in the city of Florianópolis / SC from the social assistance policy placing in the policy ofsocial assistanceto Families and Individuals (PAEFI) linked to the Specialized Center for Social Assistance (CREAS/ISLAND ). The approximation to the service CREAS/PAEFI /ISLAND occurs through the extension project developed by the Center Life and Care: studies and research on violence (CED/ UFSC), titled "Protection Network, defense and control rights: mapping risk and vulnerability in childhood in Florianopolis." In this article we seek to problematize the notions of risk and vulnerability in childhood bringing some impasses and challenges of the safety net today. We note that in the city date nineties an organization of public policy of social assistance protecting children. This route has constituted a notion of Intersectoral Network in which health, education and justice, along with community councils, plot and update notions of risk and vulnerability.

Keywords: Childhood; Risk; Vulnerability Protection Network; Policy OfSocial Assistance.

\footnotetext{
'Aluna do Curso de Pedagogia da UFSC; Pesquisadora do Núcleo de Estudos e Pesquisassobre as Violências -NUVIC. Email:s.pamelacristina@gmail.com

${ }^{2}$ Doutora em Educação. Professora da Área Educação Infantil e do Programa de Pós-Graduação em Educação da UFSC;

Coordenadora do Núcleo de Estudos e Pesquisas sobre as Violências-NUVIC. E-mailpatricia.demoraeslima@gmail.com

3 Doutoranda do Programa de Pós-Graduação em Educação da UFSC; Psicóloga do PAEFI-Ilha;Pesquisadora do Núcleo de Estudos

e Pesquisas sobre as Violências-NUVIC. E-mail:gibotega@gmail.com
} 


\section{Introdução}

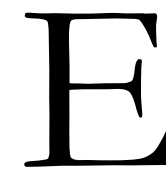

ste artigo visa apresentar o modo como a política de assistência social está organizada no município de Florianópolis/SC, problematizando com isso, os desafios e impasses produzidos pela e na rede de proteção à infância a partir da noção de risco e vulnerabilidade. Tomaremos como ponto de partida de nossas análises o Serviço de Proteção e Atendimento a Famílias e Indivíduos (PAEFI) situado dentro do Centro Especializado de Assistência Social (CREAS), para analisar como a noção de risco e vulnerabilidade transversaliza as políticas públicas voltadas as crianças em situações e contextos de violências e quais aproximações podemos fazer com a escola.

A aproximação com o serviço PAEFI-ILHA ocorre através do projeto de extensão desenvolvido pelo Núcleo Vida e Cuidado: estudos e pesquisas sobre violências (CED/UFSC), intitulado como: "REDE DE PROTEÇÃO, DEFESA E CONTROLE DOS DIREITOS: mapeamento do risco e da vulnerabilidade na infância em Florianópolis". Tal projeto relaciona-se às políticas de Atenção à Infância deflagrada pelo ECA (lei 8069/90), através de mapeamento da rede de proteção, defesa e controle dos direitos das crianças e adolescentes. Tem como principal objetivo mapear as situações de risco e vulnerabilidade da Infância em Florianópolis. A partir de uma inserção no CREAS-PAEFI-ILHA irá analisar um banco de dados que retrata os contextos de violências, nomeados como de vulnerabilidade e risco social que envolvem as crianças e adolescentes na cidade de Florianópolis. As principais ações deste projeto são: Mapear e sistematizar o quadro das violências que afetam as crianças, cruzando dados geográficos, geracionais, gênero, raça e classe;Realizar um levantamento amostral nas escolas de Educação Básica (infantil/ fundamental) sobre como as violências que acometem a infância são significadas e trabalhadas nas escolas; Organizar processos de formação aos integrantes da rede de proteção.

A noção de risco e vulnerabilidade na infância nos possibilita pensar sobre as relações de saber e poder e de como as crianças se tornam alvos das políticas públicas de assistência social. Neste contexto, a produção de dados estatísticos sustentam e revelam as estratégias de eliminação e redução dos riscos e 
vulnerabilidades, assim como deflagram quem são as crianças em risco e quais os modos, dentro daquilo que seria a norma, para assegurar às crianças contextos de segurança e proteção.

\section{Política de assistência social no município de Florianópolis}

A assistência social para se afirmar como política pública no Brasil percorreu um caminho histórico de lutas e resistências produzidas por diversos movimentos sociais, intelectuais, pesquisadores e profissionais. De modo geral, a reinvindicação neste percurso foi pelo fortalecimento da democracia e pelo deslocamento de que a área estaria associada ao assistencialismo e às formas emergenciais de atendimento à população, especialmente a que estava vinculada a pobreza. Neste cenário histórico e político, destacamos a importância da aprovação da Lei orgânica da Assistência Social (LOAS)-Lei no 8742/1993 que tem como objetivo a proteção à família, determinando-a como um dos focos de atenção da política de assistência social. A partir da Loas "a proteção social se coloca como um mecanismo contra as formas de exclusão social que decorrem de certas vicissitudes da vida, tais como a velhice, a doença, as adversidades, as privações, etc." (CRUZ e GUARESCHI, 2009, p.28). A implementação da Loas perspectiva a garantia de direitos e a responsabilização do Estado em relação ao acesso a serviços, projetos e programas.

No ano de 2004 é elaborado o plano Nacional de Assistência Social (Pnas), a partir das deliberações da IV conferencia Nacional de Assistência Social, sendo aprovado pelo Conselho Nacional de Assistência Social (Cnas). O Pnas sugere eixos para sua operacionalização: concepção, territorialidade, financiamento, controle social, monitoramento, avaliação e recursos humanos. Este processo culmina com a aprovação, em 2005, do Sistema Único de Assistência Social (SUAS). A exemplo do sistema único de saúde (SUS), o SUAS “estabelece em suas diretrizes a descentralização político-administrativa, o atendimento a quem dele necessitar, independente da contribuição à seguridade social e a participação da comunidade" (CRUZ e GUARESCHI, 2009, p.29). O SUAS passa a ser um instrumento de materialização das diretrizes da Loas. Esta nova concepção de gestão da política de assistência social tem a família como foco de atenção e o território como delimitador das ações e serviços em dois níveis de complexidade: proteção social básica e proteção social especial.

A partir do diagrama abaixo, mostraremos como está atualmente organizada a política de assistência social no município de Florianópolis. Nossa intenção aqui é dar maior visibilidade a um dos serviços dentro desta política: Serviço Proteção e Atendimento Especializado a famílias e Indivíduos (PAEFI/ILHA) com o qual temos maior contato. Queremos salientar, que cada um dos serviços possui sua historicidade, complexidade e seu nível de importância dentro da política de assistência social no município, mas que não serão analisados neste trabalho.

Diagrama I: Política de Assistência Social 
CRAS - Centro de Referência em Assistência Social

CREAS - Centro de Referência Especializado em Assistência Social

PAEFI - Serviço de Proteção e Atendimento Especializado a Famílias e Indivíduos

LA/PSC - Serviço de Proteção Social a Adolescentes em Cumprimento de Medida

Socioeducativa de Liberdade Assistida e de Prestação de Serviços à Comunidade

SEPREDI - Serviço de Proteção Especial para Pessoas com Deficiência, Idosas e suas Famílias

Centro POP - Centro de Referência Especializado para População em Situação de Rua

CREMV - Centro de Referência de Atendimento à Mulher em Situação de Violência

PETI - Programa de Erradicação do Trabalho Infantil

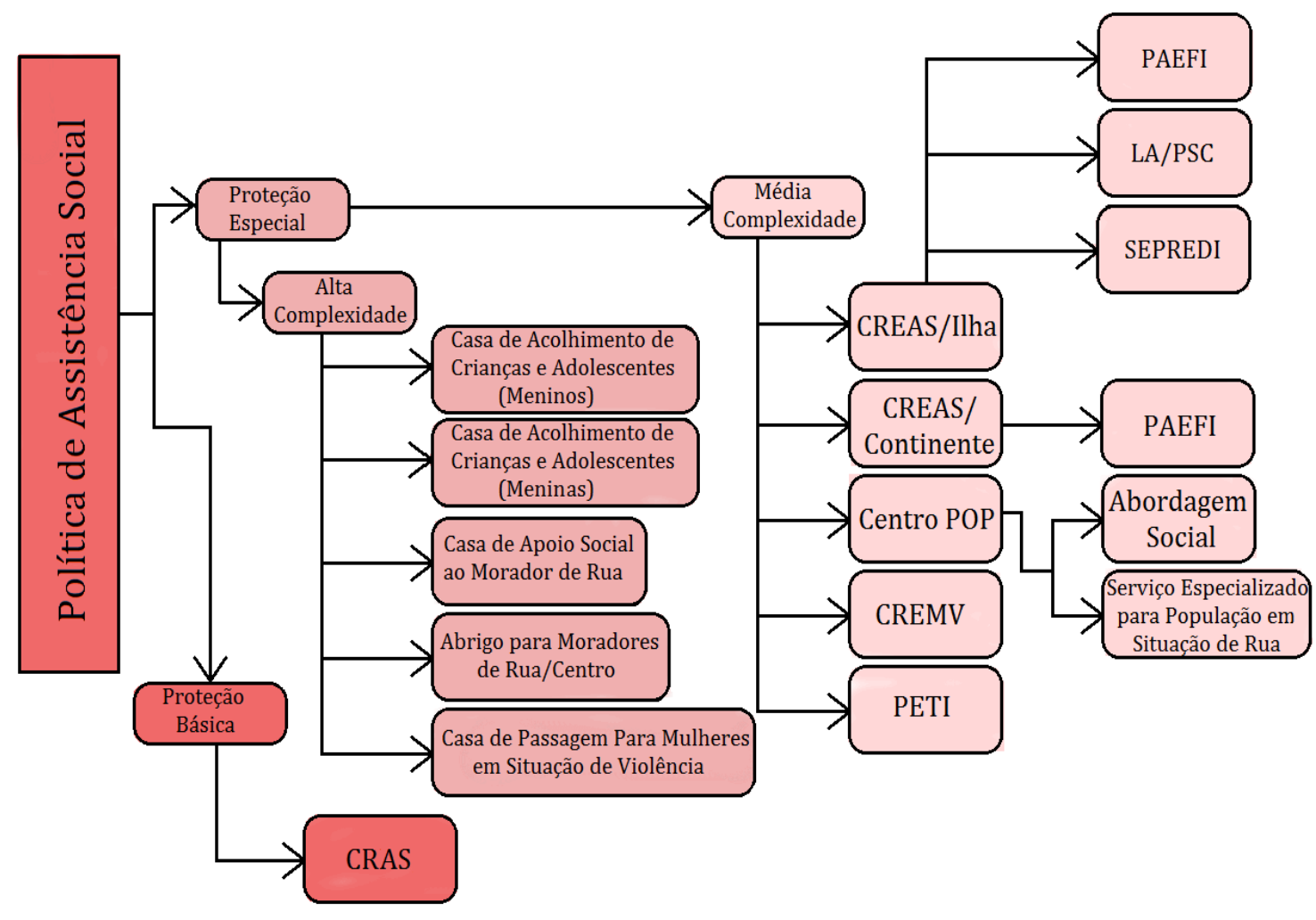

A proteção Social Básica é a porta de entrada do SUAS, caracteriza-se por prestar serviços de prevenção de famílias em "situação de vulnerabilidade e risco social" (Cartilha Pegaso,s/a) através de programas e benefícios disponibilizados pelo Governo Federal, o principal órgão responsável por viabilizar estes processos é o Centro de Referência em Assistência Social (CRAS). Na proteção social especial temos a média e alta complexidade. A Média Complexidade oferece atendimento socioassistencial às famílias e indivíduos que se encontram em situação de risco pessoal ou social por ameaça ou violação de direitos, cujos vínculos familiares e comunitários não foram rompidos. Já na Alta Complexidade oferece atendimento socioassistencial às famílias e indivíduos que se encontram em situação de risco pessoal ou social por ameaça ou violação de direitos, cujos vínculos familiares e comunitários foram rompidos.

$\mathrm{Na}$ proteção social especial temos o Centro de Referência Especializado em Assistência Social (CREAS) no qual existem programas específicos para tratar dos indivíduos em situação de direitos violados. O CREAS está vinculado ao Sistema Único de Assistência Social (SUAS), sendo este um dever 
do Estado para com os/as cidadãos e funciona em conjunto com a sociedade privada. Caracteriza-se por ser uma política social não contributiva que visa a seguridade social em trabalho conjunto com a Saúde e a Previdência Social. A partir de 2005, o SUAS, se torna "descentralizado e participativo, que tem por função a gestão do conteúdo específico da Assistência Social no campo da proteção social brasileira" (Governo do Estado de São Paulo, 2016).

No Centro de Referência Especializado em Assistência Social (CREAS) temos o Serviço de Proteção e Atendimento a Famílias e Indivíduos (PAEFI) é um serviço recente do Sistema Único de Assistência Social, aprovado em 11 de novembro de 2009, pela resolução n ${ }^{\circ}$ 109, o PAEFI atende crianças, adolescentes e suas respectivas famílias em situação de direitos violados. Entendendo por direitos violados as famílias que:

Violência física, psicológica e negligência; Violência sexual: abuso e/ou exploração sexual;Afastamento do convívio familiar devido à aplicação de medida socioeducativa ou medida de proteção; Tráfico de pessoas; - Situação de rua e mendicância; Abandono; Vivência de trabalho infantil; Discriminação em decorrência da orientação sexual e/ou raça/etnia; Outras formas de violação de direitos decorrentes de discriminações/submissões a situações que provocam danos e agravos a sua condição de vida e os impedem de usufruir autonomia e bem estar; Descumprimento de condicionalidades do PBF e do PETI em decorrência de violação de direitos. (CONSELHO NACIONAL DE ASSISTÊNCIA SOCIAL, 2009, p.18)

Dessa forma, o Serviço de Proteção e Atendimento a Famílias e Indivíduos adentra no Sistema de Garantia de Direitos sendo categorizado como Serviço de Assistência Social de Média Complexidade. Os atendimentos no PAEFI são psicossociais e objetivam restaurar e fortalecer os vínculos familiares auxiliando os indivíduos e suas famílias para que haja rompimento das violências e os/as subsidiando para que a reincidência não ocorra. Entendemos que o Sistema de Garantia dos Direitos funciona através de Redes Intersetoriais de Proteção, ou seja, organismos governamentais, não governamentais e sociedade civil trabalhando em conjunto para que os direitos das crianças e adolescentes sejam assegurados. (Faleiros, 2007)

\section{O Serviço PAEFI e a rede de proteção à infância}

Com a instituição do Estatuto da Criança e do Adolescente como lei Federal, a partir da década de 1990 uma série de políticas públicas, em prol da proteção das crianças e adolescentes, começam a ser implementadas. Tal feito deriva do artigo $\mathrm{n}^{\circ} 19$ da Convenção dos Direitos das Crianças que estabelece a obrigatoriedade dos Estados-parte de proporem medidas protetivas que assegurem os direitos de crianças e adolescentes. O Estatuto da Criança e do Adolescente no intuito de efetivar esses direitos, descentraliza a responsabilidade do Estado atribuindo autonomia e obrigações aos estados e municípios diante das políticas públicas de atenção e proteção a infância e adolescência. 
A respeito da municipalização das políticas públicas de proteção e atendimento a crianças e adolescentes o Estatuto da Criança e do Adolescente (2010, p.29-31) diz o seguinte:

Art. 86. A política de atendimento dos direitos da criança e do adolescente far-se-á através de um conjunto articulado de ações governamentais e não-governamentais, da União, dos estados, do Distrito Federal e dos municípios.

(...) Art. 88. São diretrizes da política de atendimento:

I - municipalização do atendimento;

II - criação de conselhos municipais, estaduais e nacional dos direitos da criança e do adolescente, órgãos deliberativos e controladores das ações em todos os níveis, assegurada a participação popular paritária por meio de organizações representativas, segundo leis federal, estaduais e municipais;

III - criação e manutenção de programas específicos, observada a descentralização político-administrativa;

V - integração operacional de órgãos do Judiciário, Ministério Público, Defensoria, Segurança Pública e Assistência Social, preferencialmente em um mesmo local, para efeito de agilização do atendimento inicial a adolescente a quem se atribua autoria de ato infracional;

VI - integração operacional de órgãos do Judiciário, Ministério Público, Defensoria, Conselho Tutelar e encarregados da execução das políticas sociais básicas e de assistência social, para efeito de agilização do atendimento de crianças e de adolescentes inseridos em programas de acolhimento familiar ou institucional, com vista na sua rápida reintegração à família de origem ou, se tal solução se mostrar comprovadamente inviável, sua colocação em família substituta, em quaisquer das modalidades previstas no art. 28 desta Lei;

Art. $90 . \$ 1$ As entidades governamentais e não governamentais deverão proceder à inscrição de seus programas, especificando os regimes de atendimento, na forma definida neste artigo, no Conselho Municipal dos Direitos da Criança e do Adolescente, o qual manterá registro das inscrições e de suas alterações, do que fará comunicação ao Conselho Tutelar e à autoridade judiciária.

Em âmbito municipal o Conselho Tutelar e Conselho Municipal dos Direitos das Crianças e Adolescentes (CMDCA), órgãos mencionados acima, funcionam em estreita articulação para que as políticas públicas de proteção a crianças e adolescentes se efetivem da melhor forma possível. Fiscalizados pelos Conselhos Municipais dos Direitos das Crianças, de acordo com o ECA (2010, p. 41-42) os conselhos tutelares possuem as seguintes atribuições:

I - atender as crianças e adolescentes nas hipóteses previstas nos arts. 98 e 105, aplicando as medidas previstas no art. 101, I a VII;

II - atender e aconselhar os pais ou responsável, aplicando as medidas previstas no art. 129, I a VII;

III - promover a execução de suas decisões, podendo para tanto:

a) requisitar serviços públicos nas áreas de saúde, educação, serviço social, previdência, trabalho e segurança;

b) representar junto à autoridade judiciária nos casos de descumprimento injustificado de suas deliberações.

IV - encaminhar ao Ministério Público notícia de fato que constitua infração administrativa ou penal contra os direitos da criança ou adolescente;

V - encaminhar à autoridade judiciária os casos de sua competência;

VI - providenciar a medida estabelecida pela autoridade judiciária, dentre as previstas no art. 101, de I a VI, para o adolescente autor de ato infracional;

VII - expedir notificações;

VIII - requisitar certidões de nascimento e de óbito de criança ou adolescente quando necessário; 
IX - assessorar o Poder Executivo local na elaboração da proposta orçamentária para planos e programas de atendimento dos direitos da criança e do adolescente; $\mathbf{X}$ - representar, em nome da pessoa e da família, contra a violação dos direitos previstos no art. 220, $\int 3^{\circ}$, inciso II, da Constituição Federal;

XI - representar ao Ministério Público para efeito das ações de perda ou suspensão do poder familiar, após esgotadas as possibilidades de manutenção da criança ou do adolescente junto à família natural.

Parágrafo único. Se, no exercício de suas atribuições, o Conselho Tutelar entender necessário o afastamento do convívio familiar, comunicará incontinenti o fato ao Ministério Público, prestando-lhe informações sobre os motivos de tal entendimento e as providências tomadas para a orientação, o apoio e a promoção social da família.

Os Conselhos Municipais dos Direitos das Crianças, por sua vez, possuem a missão de “deliberação e controle das ações governamentais em todas as questões relativas ao atendimento dos direitos das crianças e do adolescente. (...) Cabe a eles não somente traçar diretrizes, mas também detalhar e fiscalizar a execução, por parte do Poder Executivo, das políticas por ele deliberadas (Ardigó, 2009, p. 82)". Alicerçado no Estatuto da Criança e do Adolescente e considerando o artigo $227^{\circ}$ inciso n 4 da Constituição Federal que prevê punição severa para crimes de violência e exploração sexual contra crianças e adolescentes, nos anos 2000 é lançado o Plano Nacional de Enfrentamento da Violência Sexual Infanto-Juvenil. Este documento prevê diretrizes para a proteção e defesa dos direitos de crianças e adolescentes vitima de violência e exploração sexual, o objetivo do Plano Nacional de Enfrentamento da Violência Sexual Infanto-Juvenil é "estabelecer um conjunto de ações articuladas que permita a intervenção técnico - política e financeira para o enfrentamento da violência sexual contra crianças e adolescentes (BRASIL, 2000, p.12).”

A partir do Plano Nacional de Enfrentamento da Violência Sexual Infanto-Juvenil nasce (2001), através da Secretaria dos Direitos Humanos e sob a responsabilidade da Secretaria de Estado de Assistência Social - SEAS, o Programa Combate ao Abuso e à Exploração Sexual de Crianças e Adolescentes, conhecido como Programa Sentinela. Segundo a portaria No 878, de 3 de Dezembro de 2001 (BRASIL, 2001, p.2) os objetivos principais do Programa Sentinela visavam:

atender, no âmbito da Política de Assistência, através de um conjunto articulado de ações, crianças e adolescentes vitimados pela violência com ênfase no abuso e exploração sexual; criar condições que possibilitem às crianças e aos adolescentes vitimados e suas respectivas famílias, o resgate e a garantia dos direitos, o acesso aos serviços de assistência social, saúde, educação, justiça e segurança, esporte, lazer e cultura, guardando compromisso ético, político e a multidisciplinariedade das ações.

O Programa Sentinela foi desenvolvido pelo Governo Federal, no entanto, por estar atrelado ao Estatuto da Criança e do Adolescente, foi descentralizado e adaptado de acordo com as especificidades de cada município, cabendo ao Governo do Estado prestar subsídios para que os Municípios estruturem a política pública de proteção.

\section{Percurso histórico da Rede Intersetorial de Proteção em Florianópolis}


A portaria No 878, de 3 de Dezembro de 2001 (BRASIL, 2001) estabelece que o Programa Sentinela deverá ter como sede os Centro de Referências, em Florianópolis a estrutura localiza-se na região central da Ilha de Florianópolis. O espaço físico que hoje pertence ao CREAS/ILHA está entrelaçado com movimentos envolvendo Crianças e Adolescentes desde a década de 1990, tornando-se um espaço histórico de referência à proteção a crianças e adolescentes no município.

Os cuidados com a infância e adolescência em Florianópolis datam de 1991, com a fundação do projeto SOS Criança, o projeto tinha por objetivo atender crianças e adolescentes cujos direitos, assegurados pelo ECA, estivessem de alguma forma ameaçados. As denúncias eram feitas através de central telefônica e/ou na sede do projeto, os atendimentos por sua vez eram emergenciais não existindo acompanhamento posterior às vítimas (Silva, 2004). A partir de 1993, momento em que o Estatuto da Criança e do Adolescente começa a se firmar enquanto lei federal, os atendimentos do SOS criança são municipalizados e em 1999 este já se torna responsabilidade exclusiva do município de Florianópolis.

Adentrando nos anos 2000 o Governo Federal com a consolidação do Plano Nacional de Enfrentamento da Violência Sexual Infanto-Juvenil o Programa Sentinela chega a Florianópolis. Por já existirem projetos que tratavam dos direitos das crianças e adolescentes no município, o programa se dividiu em três projetos afim de contemplar as três linhas de ações, definidas pela portaria $\mathrm{N}^{\circ} 878$, de 3 de Dezembro de 2001, são elas: diagnóstico, atendimento psicossocial e prevenção. Nesse sentido a estrutura de atendimento as crianças vítimas de violências ficou organizada da seguinte forma:

I. Projeto Mel: Responsável pela prevenção das situações de risco envolvendo crianças e adolescentes através de palestras, oficinas e cursos.

II. SOS criança (nomenclatura utilizada até o ano de 2004, posteriormente substituída por Projeto primeiro atendimento): as atribuições deste projeto pautavam-se no atendimento inicial das vítimas e no diagnóstico das violências. Feito isto, ficava sob responsabilidade do projeto conduzir o relatório Situacional ao Conselho Tutelar.

III. Projeto Acorde: encarregava-se dos atendimentos às crianças e adolescentes cujo diagnóstico de violências era classificado como grave.

A partir de 2005, com a Norma Operacional Básica do Sistema Único de Assistência Social (NOB/SUAS) ${ }^{4}$,o Programa Sentinela sofre alterações no que diz respeito ao modo de funcionamento, os atendimentos são categorizados por três equipes de atendimento: Diagnóstico, Acompanhamento e de Trabalho em Rede. Organizando-se da seguinte maneira:

\footnotetext{
${ }^{4}$ A Norma Operacional Básica 2005 disciplina a operacionalização da gestão da política de assistência social, conforme a Constituição Federal de 1988, a LOAS e legislação complementar aplicável nos termos da Política Nacional de Assistência Social de 2004, sob a égide de construção do SUAS, abordando, dentre outras coisas: a divisão de competências e responsabilidades entre as três esferas de governo; os níveis de gestão de cada uma dessas esferas; as instâncias que compõem o processo d se relacionam; a nova relação com as entidades e organizações governamentais e não governamentais; os principais instrumentos de gestão a serem utilizados; e a forma da gestão financeira, que considera os mecanismos de transferência, os critérios de partilha e de transferência de recursos (BRASIL, 2005, p.12).
} 
I. Equipe de Trabalho em Rede: trabalha na prevenção das violências atuando com crianças, adolescentes e suas respectivas famílias através de intervenções nas escolas. Segundo o Projeto Técnico de Florianópolis (2005, p.5): “O objetivo geral se refere à implementação da articulação das ações do poder público e da sociedade civil visando assegurar a prevenção da violência doméstica contra crianças e adolescentes nos níveis primário, secundário e terciário".

II. Equipe de Diagnóstico: Tem por objeto principal "realizar diagnóstico psicossocial dos casos de violência doméstica contra crianças e adolescentes avaliando os fatores de risco e proteção (Florianópolis, 2005, p. 4)”. A equipe de diagnóstico recebe as denúncias vindas do Conselho Tutelar para então iniciar um primeiro estudo sobre a situação de violência que acomete a criança e/ou adolescente, emitindo um parecer social da situação e encaminhado para órgãos responsáveis como delegacias, Conselhos Tutelares e/ou judiciário (Alencar, 2007).

III. Equipe de Acompanhamento: tem por objetivo geral "a implantação de acompanhamento sistemático e articulado por meio de encontros grupais com crianças, adolescentes e suas famílias (Florianópolis, 2005, p.5)". A equipe de acompanhamento trabalha com crianças e/ou adolescentes que se encontram em situações possíveis de risco, após o atendimento é emitido um relatório para a equipe de diagnóstico.

O atendimento no Programa Sentinela, a partir de 2005, começa a ganhar estrutura de atendimento em rede, atendendo crianças e adolescentes não só em caráter emergencial, mas compondo uma trama sequencial de atendimento que possibilitava a criança/adolescente subsídios para lidar com as amarras geradas pelas violências. $\mathrm{O}$ atendimento das crianças em rede pelas políticas públicas veio se modificando ao longo dos anos sendo caracterizada hoje como um conjunto de "ações entre indivíduos e organizações que se tecem ou se dissolvem em todos os campos da vida societária (Zapelini, 2010, p. 129)" e que a partir disto vem pautando a necessidade de participação de todos sujeitos que compõe as políticas como atores sociais (Zapelini, 2010).

Desde a criação do SOS criança (1991) até a reformulação do Programa Sentinela (2005) percebebemos um deslocar do entendimento da criança como sujeito de direitos - por parte das políticas públicas de atenção e proteção - trazido pelo Estatuto da Criança e do Adolescente. O quê no inicio da década de 1990, devido a recente inclusão do ECA na constituição federal, aparece como preocupação normativa de assegurar os direitos da criança previstos em lei, com o adentrar dos anos 2000, se configura por caminhos outros que constituem o entendimento das crianças como sujeitos de direitos e vítimas de violências a partir da preocupação com as consequências sociais geradas do desassistir das políticas de atenção e proteção diante dessas condições.

Entendendemos que as modificações de políticas públicas acontecem por intermédio da luta por parte dos movimentos sociais, pesquisas e discussões por parte das instituições de ensino e abertura do Estado para que esse processo ocorra, percebemos que nesse movimento de pensar e repensar as reformulações das políticas de atenção e proteção as crianças qualifica os serviços ao mesmo tempo em 
que materializa novos e outros olhares em torno da condição das crianças vítimas de violências. Nesse sentido, localizamos que a finalização das atividades do Programa Sentinela no ano de 2009 com a tipificação do Serviço Único de Assistência Social imprime a necessidade refletir proteção das crianças por ângulos diferentes dos que vinham sendo pensados, que por sua vez não deslegitima o trabalho anterior, mas diz um pouco da trama que envolve o atendimento em rede.

\section{A implementação do serviço PAEFI em Florianópolis}

Como prevê Tipificação Nacional de Serviços Socioassistenciais (2009), o Serviço de Proteção e Atendimento Especializado a Famílias e Indivíduos deverá funcionar exclusivamente no Centro de Referência Especializado em Assistência Social, no município de Florianópolis, o CREAS/ILHA fica localizado na região central da ilha, no bairro agronômica.

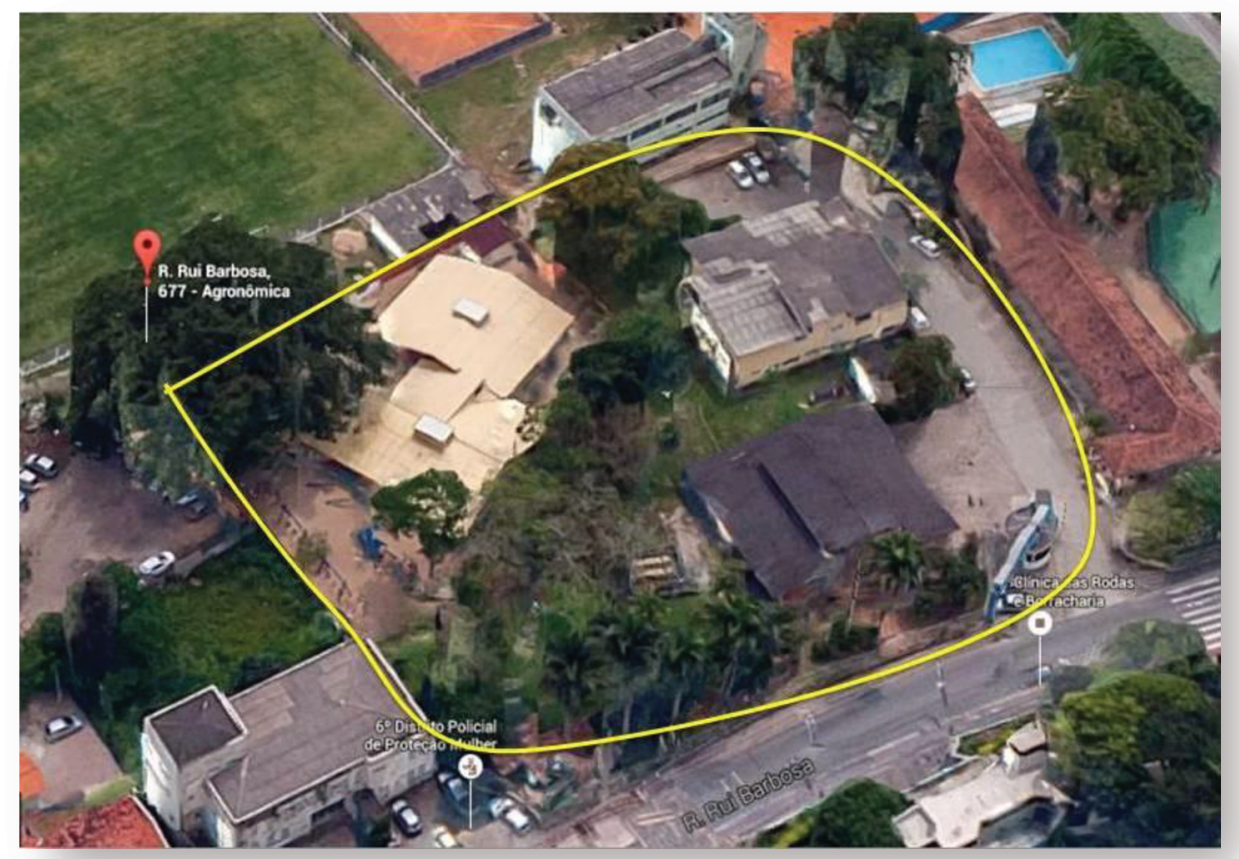

O reconhecimento do Serviço PAEFI acaba sendo localizado pela historicidade que a política pública anterior havia deixado, além disso, o fato de o Serviço de Proteção e Atendimento Especializado a Famílias e Indivíduos ter sido alocado na mesma estrutura física permite que essa associação entre uma política e outra seja feita. O espaço físico que abrigou o SOS criança, Programa Sentinela e que hoje abriga o PAEFI referencia no município, um espaço destinado a proteção de crianças e adolescentes com direitos violados. 
Em 2009, ocorrem mudanças na legislação e o Programa Sentinela passa a funcionar em conjunto com Serviço de Proteção e Atendimentos Especializado a Famílias e Indivíduos (PAEFI), sendo dissolvido por completo em 2011. Com a implementação do PAEFI o foco dos atendimentos não gira mais em torno das crianças e adolescentes com direitos violados, mas da composição familiar, tendo os seguintes objetivos (BRASIL, 2009, p.18):

Contribuir para o fortalecimento da família no desempenho de sua função protetiva; Processar a inclusão das famílias no sistema de proteção social e nos serviços públicos, conforme necessidades;

Contribuir para restaurar e preservar a integridade e as condições de autonomia dos usuários;

Contribuir para romper com padrões violadores de direitos no interior da família;

Contribuir para a reparação de danos e da incidência de violação de direitos;

Prevenir a reincidência de violações de direitos.

A partir dos objetivos estipulados a partir de 2009 reestruturam o entendimento acerca das crianças e adolescentes em situação de direitos violados, as situações de violências não são vistas isoladamente, mas dentro do ciclo familiar e social que envolve esses sujeitos. A mudança no uso dos termos que pautam os objetivos á um dado interessante, em 2005 o verbo "criar" traçava os objetivos, substituído na nova legislação por "construir". A troca de termos insere os sujeitos como atores sociais considerando seus modos de viver e estar na sociedade como constituintes desta, desmontando, portanto, o caráter prescritivo e até mesmo normativo das políticas públicas.

A tipificação prevê o atendimento psicossocial das famílias e dos indivíduos que a compõe, sendo assim os atendimentos são realizados sempre em duplas, ou seja, por um psicólogo e por um assistente social. Considerando as múltiplas faces em que as violências se apresentam e as "instituições ocupam o lugar social do cuidado, já que existem para garantir a cada criatura humana a integridade do seu desenvolvimento (Zapelini, 2010.p. 135), os atendimentos das redes de proteção realizados nesses espaços compõem elementos importantes para sinalizar em que ponto os direitos das crianças são violados. Nessa composição ritmada por diversas vozes o atendimento psicossocial do Serviço de Proteção e Atendimento Especializado a Famílias e Indivíduos se estrutura da seguinte maneira: 


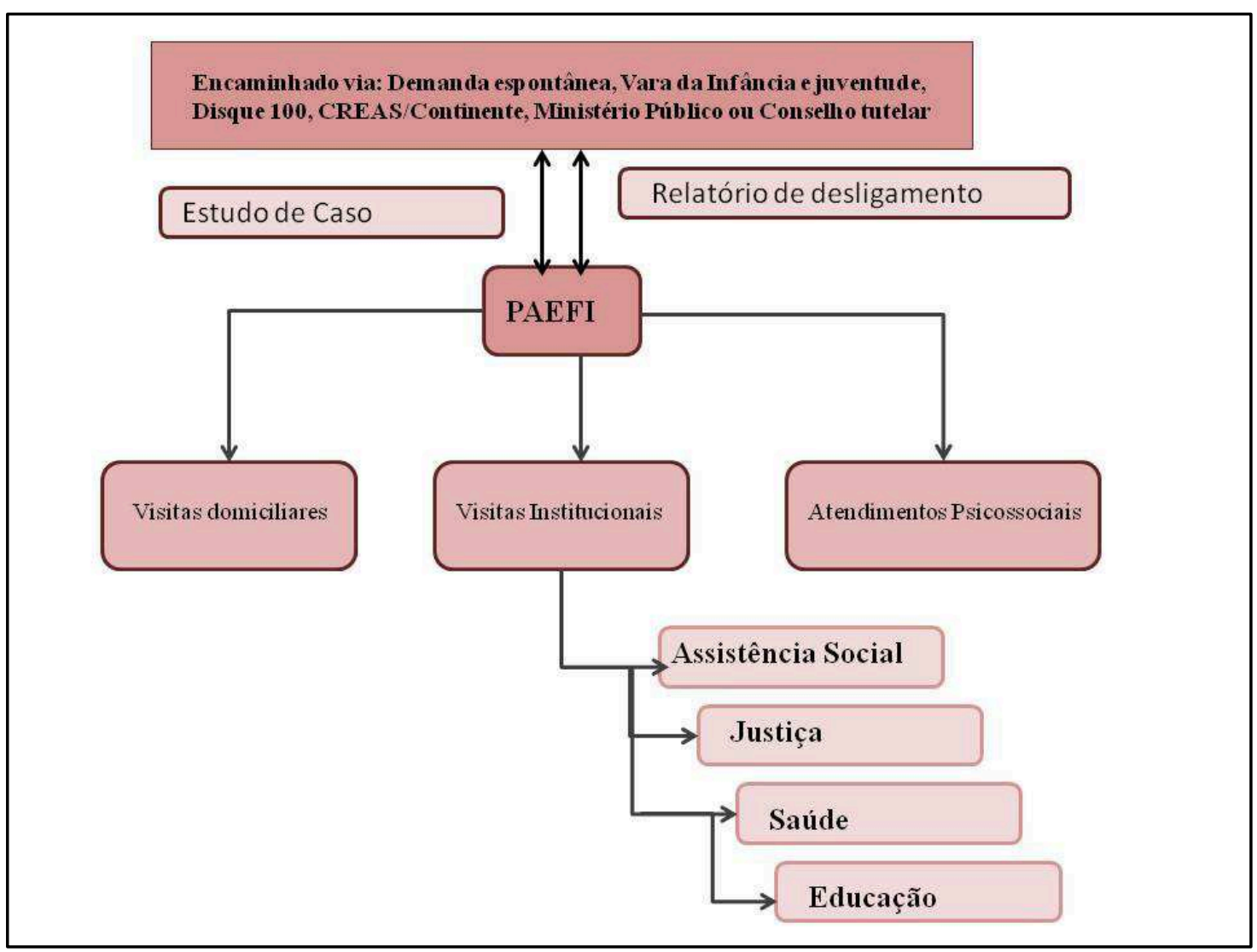

O diagrama acima tece a estrutura do atendimento em rede envolvendo, a partir da denúncia, os sujeitos que estão em volta da criança em situação de direitos violados compondo assim parte da ação de proteção, dessa forma, trabalhar num sistema de Rede de Proteção implica que todos (as) estejam envolvidos e saibam da sua importância. Ainda que as pesquisas acerca das temáticas das violências tenham se firmado como campo de pesquisa há pouco mais de três décadas, a desarticulação das redes de proteção por conta da falta de formação adequada dos/as profissionais da educação vem de longa data (Zapelini, 2010). Nesse percurso em que o desconhecimento e desarticulação das redes de proteção os corpos permanecem transitando pelos espaços educativos da mesma forma que os índices continuam a existir. Em âmbito nacional o balanço semestral do disque $100^{5}$ registrou,de janeiro a junho de 2015, o equivalente a $42.114(62,3 \%)$ de denúncias contra crianças. Ainda que os avanços em torno das políticas de proteção às crianças sejam notáveis, não podemos perder de vista os desafios encontrados pela estrutura dos atendimentos da política de proteção.

\footnotetext{
5 O Disque Direitos Humanos é um serviço de utilidade pública da Secretaria de Direitos Humanos da Presidência da República (SDH/PR) destinado a receber demandas relativas a violações de Direitos Humanos, especialmente de crianças e adolescentes, pessoas idosas, pessoas com deficiência, população LGBT, em situação de rua, em privação de liberdade, comunidades tradicionais, entre outras que atingem populações em situação de vulnerabilidade. (BRASIL, 2015, p. 11)
} 


\section{Risco e Vulnerabilidade: desafios e impassem na rede de proteção à infância}

Ao falarmos da rede de proteção à infância buscamos também dar visibilidade aos seus desafios e impasses na atualidade, dentre eles $\mathrm{o}(\mathrm{s}) \operatorname{modo}(\mathrm{s})$ em que a escola se coloca nesta rede, podendo ser de dentro e/ou de fora dela. Acreditamos que há riscos neste processo, pois ao se ver de fora poderá ter mais dificuldades em acessar as políticas públicas de garantia dos direitos das crianças. Ao se ver de dentro poderá contribuir com o debate em torno das violências que acometem as crianças e de como estas são produzidas. Ao trazer os contextos de violências em que as crianças estão inseridas, Sousa (2003) entende violência como:

(...)todo e qualquer procedimento que gera a desorganização emocional dos sujeitos, a partir de circunstâncias que os submetem à posse e ao controle de um outro, isto é, a violência é caracterizada por relações de domínio em que alguém é tratado como objeto de manipulação e gozo por um outro. ( p.83)

Para além da crítica, da escola apenas como local de conhecimento a autora nos propõe pensar nos sujeitos que compõe esse espaço juntamente com os elementos que estes sujeitos trazem consigo na tentativa de "desnormatizar" e coloca-los em contato direto consigo mesmo e com os conhecimentos produzidos por e com eles na instituição escolar.

Colocar-se dentro da rede de proteção à infância exigirá da escola possibilidade de transito entre diferentes áreas do conhecimento, por uma trama que envolve relações de poder e saber. E, por estarmos falando das crianças, apresentam-se como desafio o modo como estas são escutadas na rede, bem como os discursos produzidos em torno das crianças, de suas famílias e seus contextos, pois a relação da criança é marcada pela/na presençados adultos. Problematizar as concepções adultocêntricas em torno das infâncias e violências parece ser algo interessante dentro da rede, mas também fora dela, pois permite problematizar a própria configuração das políticas públicas e o modo como é exercido o poder e o governamento.

Talvez, estar dentro e fora da rede de proteção, permita a escola um olhar que aproxima e um olhar que distancia e neste movimento captar a complexidade que envolve uma infância em risco(Bujes, 2010), permite um exercício genealógico de pensar de onde vem a ideia de uma infância em risco, será qualquer infância que está em risco? Como a necessidade de proteger as crianças surge historicamente e socialmente? A quem devemos proteger? Do que proteger? Para que proteger? Como proteger? Assim, perceber como algumas crianças se tornam alvo do cuidado e da política de assistência social pode ser algo a ser questionado e pensado por nós.

Bujes (2010, p.168) nos coloca que o governo a vida das crianças intensifica-se especialmente quando a população se torna objeto a ser conhecido, medido e descrito em detalhes. "É o caráter calculável da população que enseja a possibilidade de intervenções cada vez mais precisas, dirigidas à miríade de problemas que afetam a vida humana, considerada em seu aspecto natural". É a produção do cálculo que vai compondo a gestão dos riscos e é a partir deste cálculo que derivam a prescrição de 
condutas adequadas. A noção de risco e, por conseguinte, as práticas decorrentes dela, estão situadas dentro de uma sociedade de segurança. Deste modo, "a segurança constitui um tipo de racionalidade formalizada pelo cálculo de probabilidades que coloca a intimidade das pessoas numa zona de governamento".

A relação entre o normal, aquilo que advém da norma, e o anormal são proliferados numa sociedade de segurança. Parte-se da norma e dela se criam as estratégias de controle dos riscos, por isto medir, classificar, comparar, testar e aproximar são práticas recorrentes e legitimadas. Cálculos estatísticos flagram os graus de maior ou menor riscos e também sustentam a condução e criação de estratégias que dizem de sua redução e eliminação. Os contextos e situações de risco, perigo e vulnerabilidades a que são expostas as crianças são a todo tempo deflagradas pelas mídias, políticas públicas se tornando uma preocupação social ampla, "com desdobramentos jurídicos, educacionais, médicos,assistenciais e de tantas outras ordens" (Bujes, 2010, p.170).

Nos dados estatísticos que apontam os riscos e vulnerabilidades que envolvem as crianças nota-se um critério que é mensurável dentro das políticas de assistência social: o nível de proteção dos adultos que estão vinculados com as crianças e seus contextos. Há insistências em se apontar os efeitos danosos daqueles que não protegem de modo adequado, ou seja, daquilo que supostamente escapa a norma. Talvez, outra saída seja nos perguntarmos pela norma e como ela é produzida? Há também uma preocupação que diz de quem sofrerá os efeitos dos riscos e vulnerabilidades, sendo cada vez mais alargada a ideia que não se restringem aos pobres. Cabe nos perguntarmos como são produzidos os riscos e as vulnerabilidades? Seriam o avesso daquilo que é seguro (um território, um tipo de família, um comportamento, etc? Uma infância em risco talvez nos mobilize a pensar, dentro e fora da rede de proteção, como se operam tentativas de deslocamentos para uma infância em segurança. E, isto não se dá fora da esfera das relações de poder. 


\section{Referências}

Ardigó, Maria Inês França. Estatuto da Criança e do Adolescente direitos e deveres. Leme/SP: Editora Cronus, 2009.

BRASIL. Estatuto da Criança e do Adolescente (ECA). 1990.

BRASIL. Lei $n^{\circ}$ 8742. Lei Orgânica de Assistência Social(LOAS). Brasília. DF, 7 de dezembro de 1993.

Bujes , Maria Isabel Edelweiss. Infância e Risco. Educ. Real., Porto Alegre, v. 35, n. 3, p. 157-174, set./dez., 2010. Disponível em: http://www.ufrgs.br/edu realidade.

CRUZ, Lilian Rodrigues e GUARESCGI, Neuza. A Constituição da Assistência Social como Política Pública: interrogações à Psicologia. IN: Políticas Públicas e Assistência Social: diálogos com as práticas psicológicas. CRUZ, Lilian Rodrigues e GUARESCGI, Neuza (Org.). Petrópolis, RJ: Vozes, 2009.

FALEIROS, V. P. A violência sexual contra crianças e adolescentes e a construção de indicadores: a crítica do poder, da desigualdade e do imaginário. In: LEAL, M. F. P; Faleiros, E. S.; Faleiros, V. P. Escola que protege: enfrentando a violência contra crianças e adolescentes. Brasília: Ministério da Educação, Secretaria de Educação Continuada, Alfabetização e Diversidade, 2007.

GIRON, Maria Francisca Rodrigues. Violências e cuidado: outros diálogos possíveis. In: ZAPELINI, Cristiane Antunes Espindola (Org.). Módulo 2: violências, Rede de Proteção e Sistema de Garantia de Direitos. Florianópolis: NUVIC-CED- UFSC-2010. Cap.2.

LIMA, Patrícia de Moraes. Rede de Proteção, Defesa e Controle dos Direitos: mapeamento do risco e da vulnerabilidade na infância em Florianópolis. Projeto de Extensão CED/UFSC, 2016.

PEGASO, Cartilha. Programa de Excelência na Gestão da Assistência Social. Publicação: Federação Catarinense de Municípios, FECAN, S/D.

SILVA, Fabiana De Macedo Soares. O Perfil do Denunciante do Projeto SOS Criança do Município de Florianópolis: Uma Análise Da Denúncia Como Instrumento De Cidadania. (Trabalho de Conclusão de Curso), Curso de Serviço Social, Departamento de Serviço Social, Universidade Federal de Santa Catarina, Florianópolis, 2004.

SOUSA, Ana Maria Borges de. Infância e violência: o que a escola tem a ver com isso? Tese de Doutorado. Porto Alegre, RS: UFRGS, 2002.

Tipificação Nacional de Serviços Socioassistenciais. Brasília, DF: Ministério do Desenvolvimento Social e Combate à Fome, 2009 